\title{
ROBOT OPERATING SYSTEM (ROS) DAN GAZEBO SEBAGAI MEDIA PEMBELAJARAN ROBOT INTERAKTIF
}

\author{
Abdul Jalil \\ abdul.jalil.fw@gmail.com \\ STMIK Handayani Makassar
}

\begin{abstract}
Abstrak
Robot merupakan sebuah prototype yang dapat dikontrol secara otomatis untuk membantu pekerjaan manusia. Beberapa unsur utama dalam membuat sistem robot adalah membangun peralatan mekanik, perangkat keras dan perangkat lunak. Keterbatasan biaya dalam membuat perangkat keras robot dan kemampuan pemrograman merupakan hambatan utama dalam mempelajari dan mengembangkan robot. Berkembangnya komunitas robot pada saat ini menjadikan Robot Operating System (ROS) dan Gazebo sebagai media interaktif untuk belajar dan membuat simulasi robot. ROS merupakan sebuah middleware yang dilengkapi dengan tools dan library untuk membuat perangkat lunak robot, sedangkan Gazebo merupakan sebuah aplikasi simulasi 3D yang dapat digunakan untuk membangun desain perangkat keras robot. Dalam penulisan ini, peneliti membuat sebuah simulasi robot penghindar benda menggunakan sensor lidar dan kamera, simulasi robot ini dibangun menggunakan ROS dan Gazebo dan dapat digunakan sebagai media pembelajaran robot interaktif.
\end{abstract}

Kata Kunci: Robot Operating System (ROS), Gazebo, Robot.

\begin{abstract}
A robot is a prototype that is able to control by automatically to help the human work. Some of the parts to build a robot system are making the mechanical system, hardware, and software. The limitation of cost to make the robot hardware and programming skills are an obstacle to learn and develop the robot system. The development of the robot community nowadays makes the Robot Operating System (ROS) and Gazebo as an interactive media to learn and make the robot simulation. ROS is a middleware that equipped with tools and libraries to create a robot software, while Gazebo is a $3 \mathrm{D}$ simulation application to build a robot hardware design. On this paper, the researcher makes a robot simulation to avoid the object using Lidar sensor and camera, the simulation has developed using ROS and Gazebo that be able to use as a media for robot learning interactive.
\end{abstract}

Keyword: Robot Operating System (ROS), Gazebo, Robot.

\section{Pendahuluan}

Perkembangan Robot saat ini bukan hanya digunakan untuk keperluan industri dan pabrik, namun sudah menjadi bahan pelajaran penting baik di sekolah-sekolah maupun di perguruan tinggi. Maraknya perlombaan dan kontes robot menjadi bukti bahwa dunia robot sudah tidak asing lagi di mata masyarakat serta sudah menjadi ajang untuk mengadu bakat dibidang robotika. Penerapan robot sebagai media pembelajaran telah diaplikasikan pada sebuah prototype robot humanoid [1], robot ini dapat berinteraksi dengan manusia ketika manusia berjalan di depan robot. Robot secara harfiah diciptakan untuk dapat membantu dan mempermudah pekerjaan manusia serta telah di aplikasikan pada industri, rumah sakit, militer, dan kehidupan masyarakat. Robot berasal dari bahasa Chech yaitu robota yang berarti 'pekerja'. Kata robot di perkenalkan dalam bahasa Inggris pada tahun 1921 oleh Wright Karel Capek pada sebuah drama, "Rossum's Universal Robots" (RUR) [2].

Berkembangnya kemajuan teknologi mengharuskan keterlibatan akademisi untuk mewujudkan industri 4.0, adapun salah satu bidang industri 4.0 adalah robotics and human-robot collaboration [3]. Peran sekolah dan perguruan tinggi dalam mengajarkan robot kepada siswa dan mahasiswa menjadi salah satu unsur keberhasilan akademis dalam membangun revolusi industri 4.0. Namun keterbatasan fasilitas dan mahalnya perangkat keras robot menjadi salah satu hambatan dalam mengajar dan memperkenalkan robot di dunia akademisi. Berkembangnya ilmu pengetahuan robot saat ini membuat para peneliti dan komunitas membangun Robot Operating System (ROS) dan Gazebo sebagai aplikasi untuk membuat simulasi robot baik dari sisi perangkat lunak maupun perangkat keras. Pada penulisan ini peneliti akan memaparkan bagaimana ROS dan Gazebo dapat digunakan sebagai media pembelajaran robot interaktif dengan melihat beberapa penelitian terkait serta mensimulasikan sebuah mobile robot yang dapat menghindar dari benda ketika beroperasi menggunakan sensor Lidar dan kamera. 


\section{Metode}

Pada penelitian ini dibangun sebuah simulasi robot yang dapat menghindari objek menggunakan sensor lidar dan kamera. Simulasi robot tersebut dibangun menggunakan ROS untuk membangun perangkat lunak robot dan Gazebo untuk membangun perangkat keras robot. Kedua aplikasi ini kemudian digunakan untuk menghasilkan sebuah simulasi robot yang dapat diaplikasikan sesuai dengan kondisi lingkungan yang sebenarnya.

\subsection{Pengertian ROS}

ROS adalah Sistem Operasi Robot bersifat open source yang didalamnya terdapat library dan tools untuk membuat perangkat lunak robot [4][5][6][7][8]. ROS merupakan sebuah middleware robot yang dapat menghubungkan perangkat keras robot dengan sistem operasi komputer secara fleksibel. ROS bertujuan untuk memudahkan pengembang robot dalam membuat perangkat lunaknya tanpa harus membuat kode sumber dari awal serta dapat dikembangkan bersama-sama. Berikut adalah gambar logo ROS.

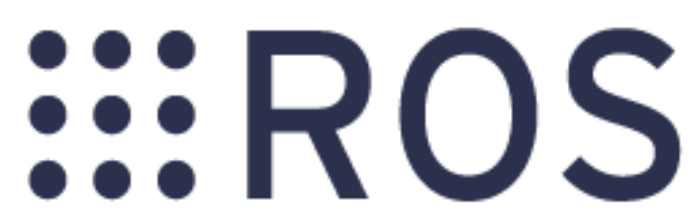

Gambar 1. Logo ROS [14]

\subsection{Sejarah ROS}

Menurut beberapa sumber [4][5][6][9], ROS merupakan sebuah project besar yang dikembangkan oleh banyak komunitas dan peneliti robot. Sejak pertengahan tahun 2000, Universitas Stanford telah melibatkan STanford Al Robot (STAIR) dan Personal Robot (PR) untuk menciptakan sebuah prototype perangkat lunak fleksibel dan dinamis yang dapat digunakan pada sistem robotika. Menurut pengembangnya [15], mereka telah mendesain ROS untuk mensupport filosofi modular dan tools berbasis pengembangan software.

ROS mulai dikembangkan sejak November 2007 oleh Stanford Artificial Intelligence Laboratory (SAIL) yang disupport oleh Stanford Al Robot Project. Pada tahun 2008, Willow Garage yang merupakan sebuah Institute penelitian robot telah bekerjasama dengan lebih dari 20 Institusi untuk saling berkolaborasi dan mengembangkan ROS dalam model pengembangan federasi. ROS bersifat open-source yang berlisensi BSD dan ditulis menggunakan bahasa pemrograman $\mathrm{C}++$ dan Python. Platform ini secara bertahap banyak digunakan dan dikembangkan oleh komunitas dan peneliti robot.

\subsection{Perkembangan ROS}

Hingga saat ini ROS terus dikembangkan oleh banyak peneliti serta banyak digunakan untuk pengembangan proyek otomasi, baik itu untuk keperluan industri, penelitian dan pendidikan. ROS dijadwalkan rilis setiap bulan Mei dengan support sistem antara dua hingga lima tahun. Berikut adalah tabel perkembangan distribusi ROS.

Tabel 1. Jenis-jenis distribusi ROS dan perkembangannya [12].

\begin{tabular}{|l|l|l|}
\hline \multicolumn{1}{|c|}{ Distro } & \multicolumn{1}{c|}{ Tanggal Rilis } & \multicolumn{1}{c|}{ Support Sistem } \\
\hline ROS Melodic Morenia & Mei 2018 & Mei 2023 \\
\hline ROS Lunar Lorgerhead & 23 Mei 2017 & Mei 2019 \\
\hline ROS Kinetic Kame & 23 Mei 2016 & April 2021 \\
\hline ROS Jade Turtle & 23 Mei 2015 & Mei 2017 \\
\hline ROS Indigo Igloo & 22 Juli 2014 & April 2019 \\
\hline ROS Hydro Medusa & 4 September 2013 & Mei 2015 \\
\hline ROS Groovy Galapagos & 31 Desember 2012 & Juli 2014 \\
\hline ROS Fuerte Turtle & 23 April 2012 & - \\
\hline ROS Electric Emys & 30 Agustus 2011 & - \\
\hline ROS Diamondback & 2 Maret 2011 & - \\
\hline ROS C Turtle & 2 Agustus 2010 & - \\
\hline ROS Box Turtle & 2 Maret 2010 & - \\
\hline
\end{tabular}


Berdasarkan informasi tabel 1 dapat di lihat bahwa ROS terus berkembang dan di aplikasikan sejak tahun 2010. Hingga saat ini ROS terus dikembangkan menjadi ROS2 oleh beberapa peneliti yang saling berkontribusi [10][11]. Tujuan pengembangan ROS2 adalah untuk mengembangkan sistem yang sudah ada pada ROS. Salah satu perbedaan antara ROS dan ROS2 adalah terletak pada sistem komunikasinya, dimana ROS menggunakan TCP/UDP untuk saling berkomunikasi sedangkan ROS2 menggunakan Data Distributed System (DDS), selain itu ROS2 sudah mensupport untuk sistem komunikasi multi-robot.

\subsection{Konsep ROS}

ROS memiliki 3 konsep yaitu level filesystem, level grafik komputasi dan level komunitas [13]. Level filesystem merupakan level sumber daya ROS yang ada pada sistem. Langkah awal saat menggunakan atau mengembangkan ROS adalah dengan membuat konsep layaknya sebuah sistem operasi. Pada sebuah filesystem ROS terdapat folder, dan setiap folder mempunyai deskripsi file yang berbeda-beda sesuai dengan fungsinya masing-masing [5]. Level filesystem ROS meliputi packages, metapackages, packages manifests, metapackage manifests, message dan service.

Level grafik komputasi adalah jaringan peer-to-peer pada proses ROS yang memproses data bersama-sama [13]. ROS akan saling terkoneksi ketika semua proses saling terhubung. Setiap node dalam sistem akan saling terhubung, melihat informasi dan berinteraksi dengan node lainnya. Secara mendasar grafik komputasi ROS terdiri atas level nodes, master, parameter server, message, topics, services, dan bags. Konsep level komunitas ROS adalah komunitas dapat membagi resource ROS secara terpisah untuk dapat saling bertukar pengetahuan dan perangkat lunak [5]. Resource tersebut meliputi distribusi ROS, repository, ROS wiki, bug ticket system, mailing list, ROS answer dan blog.

\subsection{Gazebo}

Gazebo merupakan sebuah aplikasi simulasi open source yang dapat mengolah perkembangan mesin dinamis yang dikembangkan oleh Open Source Robotics Foundation [25]. Gazebo dapat mensimulasikan perancangan robot serta melatih sistem artificial intelligent dengan kemampuan simulasi yang akurat, perancangan simulasi dapat di desain baik didalam maupun diluar ruangan yang kompleks [26]. Aplikasi gazebo beroperasi pada sistem operasi Linux dengan kemampuan grafis yang cukup tinggi. Berikut adalah gambar dari tampilan aplikasi simulasi Gazebo.

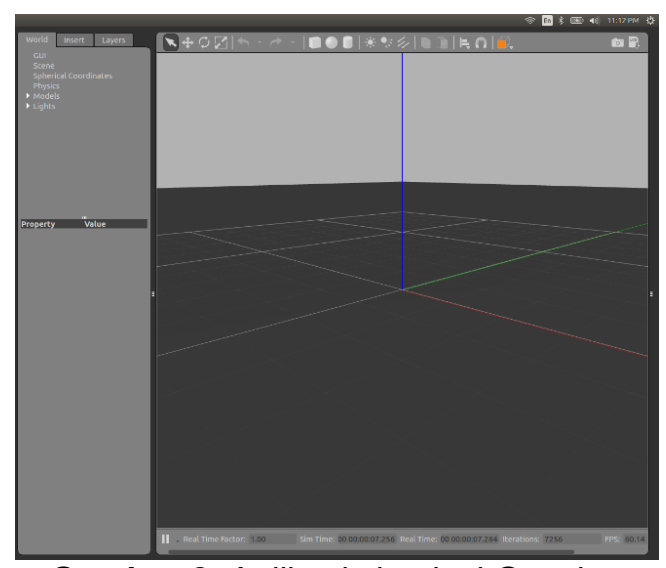

Gambar 2. Aplikasi simulasi Gazebo.

\section{Hasil dan Pembahasan}

ROS dan Gazebo adalah aplikasi robot open source yang sangat baik digunakan untuk media pembelajaran robot. ROS merupakan middleware yang dapat membantu dalam pembuatan aplikasi robot, mulai dari driver, state-of-the-art algoritma serta tools yang powerfull untuk membuat projek robotika, sedangkan Gazebo adalah sebuah aplikasi simulasi 3D yang akurat dan efisien untuk simulasi robot baik didalam maupun diluar ruangan. Dukungan grafis yang sangat tinggi dan keakuratan sudut gerak robot membuat gazebo sangat baik digunakan untuk simulasi gerak robot. Penggabungan ROS dan Gazebo sebagai simulasi robot telah banyak digunakan untuk membantu peneliti dalam membuat robot. Berikut adalah beberapa penelitian simulasi robot menggunakan ROS dan Gazebo.

Pada penelitian [16], telah dibangun sebuah framework untuk simulasi sistem quadrotor UAV menggunakan ROS dan Gazebo. Sistem penerbangan yang saling terintegrasi menggunakan tools 
ROS memberikan akses simulasi quadrotor UAV dengan sistem low level sensor pada sistem penerbangan yang dinamis menggunakan sensor LIDAR dan SLAM sebagai aplikasi open source. Penelitian lainnya adalah menggunakan ROS dan Gazebo untuk simulasi tiga dimensi dalam menentukan lokasi dan pemetaan menggunakan algoritma mapping. Algoritma ini telah diterapkan pada sistem multi-robot gMapping dan multi-robot Hector Mapping [17].

Pada penelitian lain, sebuah robot kinetic dibuat menggunakan ROS dan disimulasikan pada model tiga dimensi Gazebo. Robot tersebut diharapkan dapat diaplikasikan untuk kebutuhan masyarakat [18]. Sebuah mobile robot simulasi tiga dimensi telah diaplikasikan menggunakan ROS dan Gazebo, simulasi robot tersebut digunakan sebagai robot yang dapat bernavigasi secara outonomous [19]. ROS dan Gazebo juga telah diaplikasikan untuk membuat simulasi RoboCup, yaitu robot yang disimulasikan untuk bermain bola [20].

Sebuah robot crawler dengan model tiga dimensi telah diaplikasikan menggunakan ROS dan Gazebo, robot ini disimulasi untuk melihat performa model dan simulasi robot crawler rusia menggunakan visualisasi motion ROS/RVIz [21]. Robot pemrograman jaringan telah diaplikasikan menggunakan ROS untuk kebutuhan pelatihan dan pendidikan, robot ini disimulasikan menggunakan ROS dan jaringan [22]. Simulasi robot manipulator telah diaplikasikan menggunakan ROS dan Gazebo untuk mengimplementasikan sebuah kontrol robot pada sebuah sistem waktu yang singkat [23]. Penelitian lainnya adalah membuat simulasi robot lengan yang dapat bergerak sebanyak lima titik derajat menggunakan (DOF) servo visual, robot ini disimulasikan menggunakan ROS dan Gazebo [24].

Penulis telah membuat sebuah simulasi mobile robot yang dapat mendeteksi benda kemudian menghindarinya menggunakan sensor Lidar dan Kamera. Fungsi sensor Lidar adalah untuk mendeteksi objek berdasarkan informasi data dari cahaya laser, sedangkan kamera berfungsi untuk mendeteksi objek berupa gambar yang kemudian diolah oleh sistem robot. Pada gambar 3 dapat dilihat model desain simulasi dari robot penghindar benda. Robot yang didesain tersebut dapat menghindar dari benda ketika berada didepan robot. Gambar 4 memperlihatkan bagaimana gerak navigasi robot pada saat menghindar dari benda.

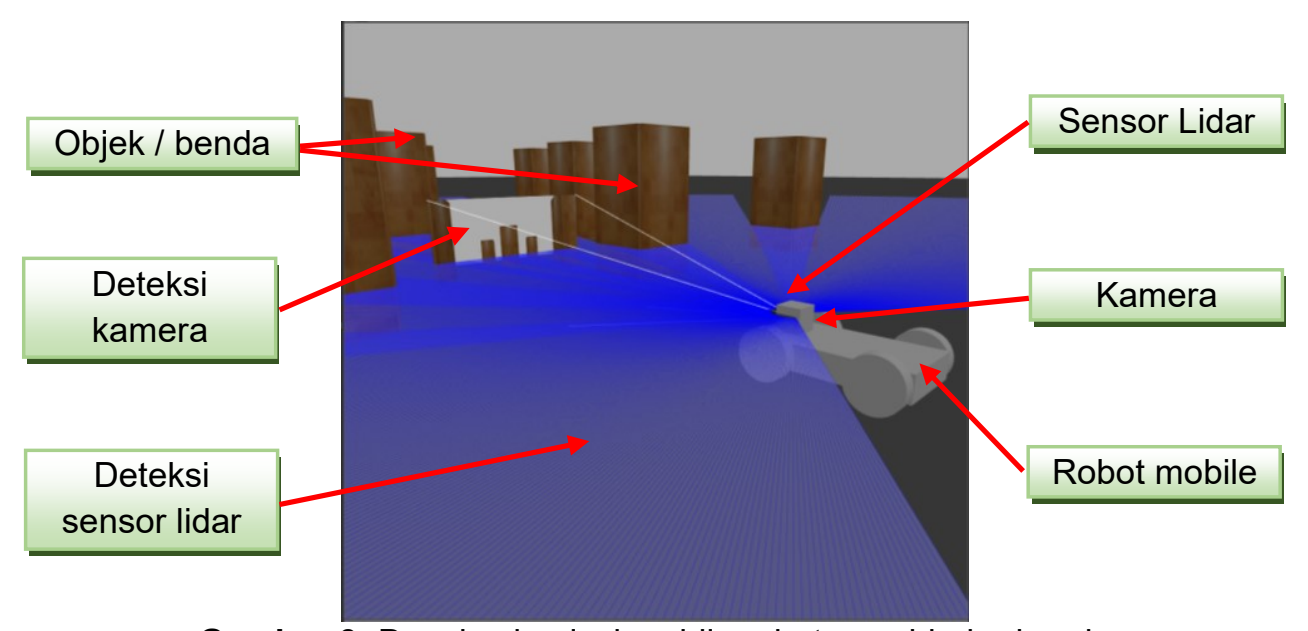

Gambar 3. Desain simulasi mobile robot penghindar benda

Berdasarkan penelitian yang telah dilakukan oleh beberapa peneliti dapat dilihat bahwa ROS dan Gazebo dapat dijadikan sebagai media pembelajaran robot interaktif, baik itu dikalangan akademisi, peneliti, penghobi dan industri. Simulasi robot menggunakan Gazebo akan sangat efektif jika dipadukan dengan ROS, dimana Gazebo berfungsi untuk membuat desain perangkat keras robot sedangkan ROS untuk membangun perangkat lunaknya.

Mahalnya perangkat keras robot membuat banyak pelajar dan siswa dikalangan akademisi tidak mampu untuk membeli bahan-bahan robot. Ini akan menghambat mereka dalam melakukan pembelajaran robot. Dengan adanya ROS dan Gazebo diharapkan akan sangat membantu bagi pelajar, mahasiswa dan masyarakat yang ingin belajar robot secara mandiri maupun akademis. Berkembangnya komunitas ROS yang ada saat ini akan lebih memudahkan bagi siapa saja yang ingin mengembangkan robot tanpa harus mengeluarkan biaya yang cukup mahal dan mudah. Terdapat banyak sumber kode yang dapat dikembangkan untuk membuat robot sendiri tanpa harus membuat kode program dari awal. Pengembang dan peneliti cukup melihat source yang ada 
sebelumnya kemudian mengembangkannya sesuai dengan robot yang akan dibangun. Selain itu dukungan website dan grup komunitas yang besar membuat ROS semakin menjanjikan untuk dijadikan sebagai sistem operasi robot masa depan.
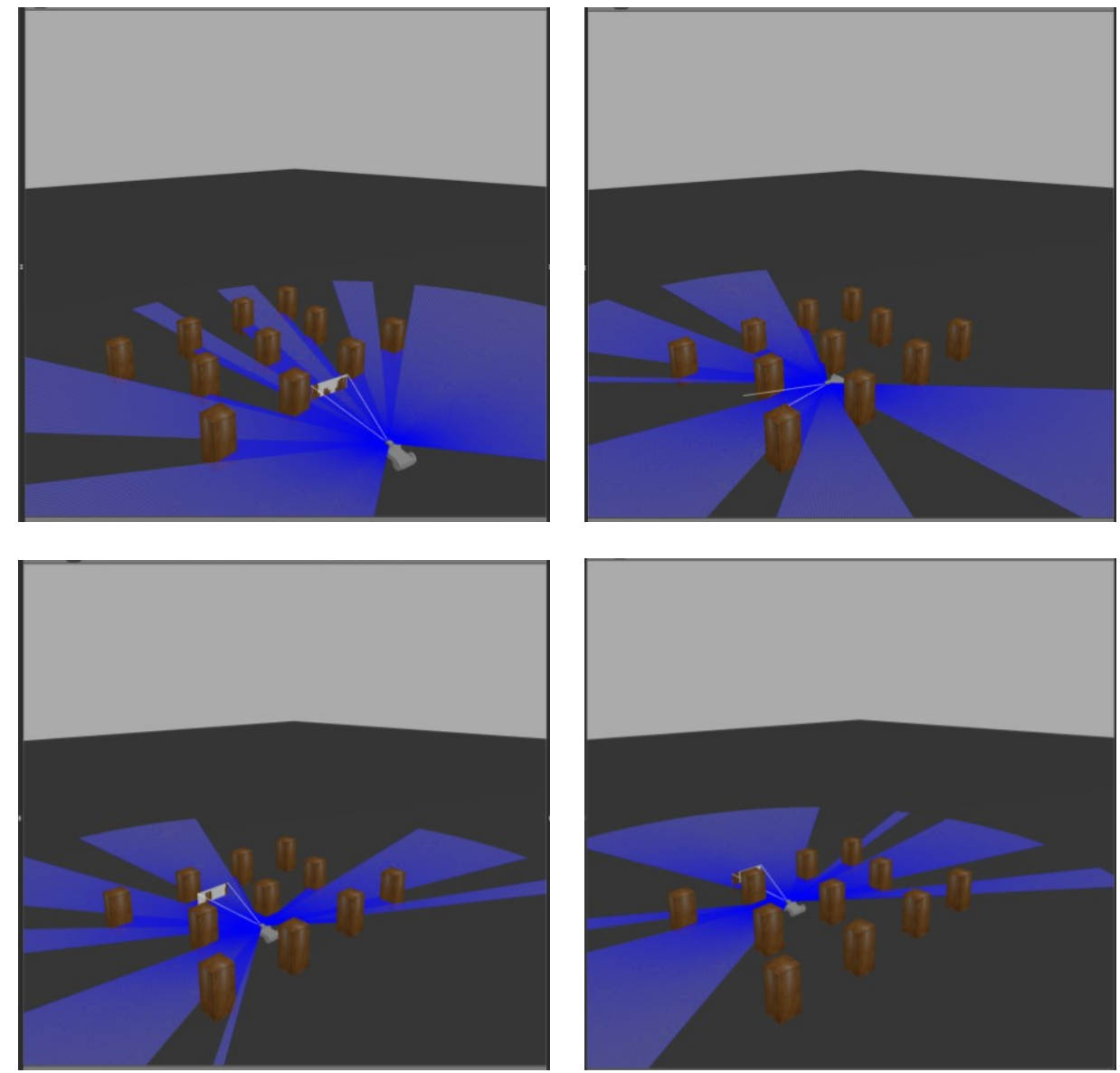

Gambar 4. Arah navigasi robot saat menghindar dari benda

\section{Kesimpulan dan Saran}

Simulasi robot penghindar benda/objek telah disimulasikan menggunakan ROS dan Gazebo. Kedua aplikasi tersebut dapat digunakan untuk membuat dan menjalankan simulasi robot sesuai dengan keadaan lingkungan yang sebenarnya. Tantangan revolusi industri 4.0 dalam mengembangkan robotika menjadikan ROS dan Gazebo dapat digunakan sebagai media pembelajaran robot interaktif sehingga peran sekolah dan perguruan tinggi dalam mengajarkan robot kepada masyarakat akan lebih efisien, efektif, dan lebih murah. Saran untuk penelitian kedepannya adalah desain robot yang telah disimulasikan akan dilanjutkan dengan menerapkan langsung pada robot nyata.

\section{Daftar Pustaka}

[1] A. Jalil, "Rancang Bangun Robot Humanoid," Proceeding, Konferensi Nasional Ilmu Komputer (KONIK APTIKOM), ISSN: 2338-2899, 2016.

[2] Taufiq Dwi Septian Suyadhi, "Buku Pintar ROBOTIKA. Bagaimana Merancang dan Membuat Robot Sendiri," Yogyakarta: Penerbit Andi, 2010.

[3] Hoedi Prasetyo,Wahyudi Sutopo, "INDUSTRI 4.0: TELAAH KLASIFIKASI ASPEK DAN ARAH PERKEMBANGAN RISET," Jurnal Teknik Industri, Vol. 13, No. 1, Januari 2018.

[4] Aaron Martinez and Enrique Fernandez, "Learning ROS for Robotics Programming," Published by Packt Publishing Ltd. Livery Place, Birmingham B3 2PB, UK. ISBN 978-1-78216-144-8, 2013.

[5] Enrique Fernandez, Luiz Sanchez Crespo, Anil Mahtani and Aaron Martinez, "Learning ROS for Robotics Programming second edition," Published by Packt Publishing Ltd. Livery Place, Birmingham B3 2PB, UK. ISBN 978-1-78398-758-0, 2015. 
[6] http://www.ros.org/. [online], diakses pukul 20.05, tanggal 11 Oktober 2018.

[7] J. M. O'Kane, "A Gentle Introduction to ROS," Independently published, available at http://www.cse.sc.edu/_jokane/agitr/, 2013.

[8] Andreas Bihlmaier, Heinz W"orn, "Increasing ROS Reliability and Safety through Advanced Introspection Capabilities," Institute for Anthropomatics and Robotics (IAR), Intelligent Process Control and Robotics Lab (IPR), Karlsruhe Institute of Technology (KIT).

[9] http://www.ros.org/history/. [online], diakses pukul 15.20, tanggal 13 Oktober 2018.

[10] http://design.ros2.org/. [online], diakses pukul 16.40, tanggal 14 Oktober 2018.

[11] http://design.ros2.org/articles/changes.html. [online], diakses pukul 14.15, Tanggal 16 Oktober 2018.

[12] http://wiki.ros.org/Distributions. [online], diakses pukul 15.20, tanggal 17 Oktober 2018.

[13] http://wiki.ros.org/ROS/Concepts. [online], diakses pukul 10.40, tanggal 19 Oktober 2018.

[14] http://www.ros.org/wp-content/uploads/2013/10/rosorg-logo1.png. [online], diakses pukul 14.53, tanggal 21 Oktober 2018.

[15] Morgan Quigley, Brian Gerkey, Ken Conley, Josh Faust, Tully Footey, Jeremy Leibs, Eric Berger, Rob Wheeler, Andrew Ng, "ROS: an open-source Robot Operating System," Computer Science Department, Stanford University, Stanford, CA. Willow Garage, Menlo Park, CA. Computer Science Department, University of Southern California.

[16] Johannes Meyer, Alexander Sendobry, Stefan Kohlbrecher, Uwe Klingauf1 dan Oskar von Stryk, "Comprehensive Simulation of Quadrotor UAVs using ROS and Gazebo," Department of Mechanical Engineering, TU Darmstadt, Germany. Department of Computer Science, TU Darmstadt, Germany.

[17] Erkan Uslu, Furkan Cakmak, Nihal Altuntas, Salih Marangoz, Mehmet Fatih Amasyali and Sirma Yavuz, "An Architecture for Multi-Robot Localization and Mapping in the Gazebo/Robot Operating System Simulation Environment," Simulation: Transactions of the Society for Modeling and Simulation International. p 1-10, DOI: 10.1177/0037549717710098, 2017.

[18] Thomas Linner, Alaguraj Shrikathiresan, Maxim Vetrenko, Bernhard Ellmann dan Thomas Bock, "Modeling and Operating Robotic Environments Using Gazebo/Ros," Chair for Building Realization and Robotics, Technische Universität München, Germany dan Building Technology and Construction Management, IIT Madras, India.

[19] Kenta Takaya, Toshinori Asai, Valeri Kroumov, dan Florentin Smarandache, "Simulation Environment for Mobile Robots Testing Using Ros and Gazebo," 20th International Conference on System Theory, Control and Computing (ICSTCC), October 13-15, Sinaia, Romania, 2016.

[20] Weijia Yao, Wei Dai, Junhao Xiao, Huimin Lu, Zhiqiang Zheng, "A Simulation System Based on ROS and Gazebo for RoboCup Middle Size League," Proceedings of the 2015 IEEE Conference on Robotics and Biomimetics Zhuhai, China, December 6-9, 2015.

[21] Maxim Sokolov, Roman Lavrenov, Aidar Gabdullin, llya Afanasyev dan Evgeni Magid, "3d Modelling and Simulation of a Crawler Robot in Ros/Gazebo," MATEC Web of Conferences, Conference Paper December 2016. DOI: 10.1145/3029610.3029641, 2016.

[22] Gustavo A. Casa n, Enric Cervera, Amine A. Moughlbay, Jaime Alemany dan Philippe Martinet, "ROS-based Online Robot Programming for Remote Education and Training, " 2015 IEEE International Conference on Robotics and Automation (ICRA) Washington State Convention Center Seattle, Washington, May 26-30, 2015.

[23] Wei Qian, Zeyang Xia, Jing Xiong, Yangzhou Gan, Yangchao Guo, Shaokui Weng, Hao Deng, Ying Hu, Jianwei Zhang, "Manipulation Task Simulation using ROS and Gazebo," Proceedings of the 2014 IEEE International Conference on Robotics and Biomimetics, Bali, Indonesia, December 5-10, 2014.

[24] Parisa Masnadi Khiabani, Babak Sistanizadeh Aghdam, Javad Ramezanzadeh and Hamid D. Taghirad, "Visual Servoing Simulator by Using ROS and Gazebo," Proceedings of the $4^{\text {th }}$ International Conference on Robotics and Mechatronics, Tehran, Iran, October 26-28, 2016.

[25] Enrico Mingo Hoffman, Silvio Traversaro, Alessio Rocchi, Mirko Ferrati, Alessandro Settimi, Francesco Romano, Lorenzo Natale, Antonio Bicchi, Francesco Nori, Nikos G. Tsagarakis, "Yarp Based Plugins for Gazebo Simulator," J. Hodicky (Ed.): MESAS 2014, LNCS 8906, pp. 333-346, 2014.

[26] http://gazebosim.org/. [online], diakses pukul 19.40, tanggal 25 Oktober 2018. 